LAS PRÁCTICAS DE RIESGO EN LA INFANCIA, UNA MIRADA DESDE LA SUBJETIVIDAD POLÍTICA

Juan Pablo Jiménez Montenegro

Laura Juliana Pachón Rodríguez

Flor Marcela Ramos López

\author{
Director: \\ Juan Carlos Garzón
}

UNIVERSIDAD PEDAGÓGICA NACIONAL

FACULTAD DE EDUCACIÓN

MAESTRÍA EN DESARROLLO EDUCATIVO Y SOCIAL

BOGOTÁ

2017 


\begin{tabular}{|c|c|}
\hline \multicolumn{2}{|c|}{ FORMATO } \\
\hline \multicolumn{2}{|c|}{ RESUMEN ANALÍTICO EN EDUCACIÓN - RAE } \\
\hline Código: FOR020GIB & Versión: 01 \\
\hline Fecha de Aprobación: 10-10-2012 & Página 1 de 3 \\
\hline
\end{tabular}

\begin{tabular}{||l|l||}
\hline \multicolumn{2}{|c||}{ 1. Información General } \\
\hline Tipo de documento & Tesis de grado \\
\hline Acceso al documento & Biblioteca Universidad Pedagógica Nacional-Biblioteca Central \\
\hline Titulo del documento & $\begin{array}{l}\text { Las prácticas de riesgo en la infancia, una mirada desde la subjetividad } \\
\text { política }\end{array}$ \\
\hline Autor(es) & $\begin{array}{l}\text { Jiménez Montenegro, Juan Pablo; Pachón Rodríguez, Laura Juliana; } \\
\text { Ramos López Flor Marcela. }\end{array}$ \\
\hline Director & Garzón Juan Carlos \\
\hline Publicación & Bogotá. Universidad Pedagógica Nacional, 2017. 38 p. \\
\hline Unidad Patrocinante & $\begin{array}{l}\text { Fundación Centro Internacional de Educación y Desarrollo Humano- } \\
\text { CINDE }\end{array}$ \\
\hline Palabras Claves & $\begin{array}{l}\text { INFANCIA; RIESGO; PRÁCTICAS DE RIESGO; SUBJETIVIDAD } \\
\text { POLITICA INFANTIL; ÁMBITO ESCOLAR }\end{array}$ \\
\hline
\end{tabular}

\section{Descripción}

Tesis de grado que da cuenta de los resultados de la investigación realizada alrededor de las prácticas de riesgo que asumen niños y niñas en el ámbito escolar y cómo éstas influyen en la configuración de su subjetividad política, de allí que las comprensiones alrededor del riesgo, las condiciones del contexto y las formas en que se interroga el orden institucional se convierten en inquietudes específicas sobre los cuales se orienta el estudio. Conforme a ello el esquema metodológico se suscribió desde una mirada interpretativa - cualitativa de corte exploratorio que permitió el reconocimiento de las relaciones entre riesgo y subjetividad política en la infancia y a partir de allí los significados y las acciones que tienen lugar no solo desde el escenario escolar sino en el marco de una sociedad posmoderna incidente en las reflexiones, intenciones, decisiones y tensiones que entre niños, niñas, adultos e instituciones se originan alrededor del tema.

\section{Fuentes}

Acevedo, A., Vargas, F., (2000) Sociología del riesgo, Estudios sobre las culturas contemporáneas, VI, (11), 149-156. Recuperado de http://www.redalyc.org/articulo.oa?id=31601109

Beck, U., (1998). La sociedad del riesgo, hacia una nueva modernidad. Recuperado de http://davidhuerta.typepad.com/files/beck-ulrich-la-sociedad-del-riesgo-hacia-una-nueva-modernidad.pdf

Bustelo, E.S., (2005) Infancia en indefensión. Salud colectiva, 1(3), 253-284. Recuperado de http://www.scielo.org.ar/scielo.php?pid=S1851-82652005000300002\&script=sci abstract

Bustelo, E.S., (2007) El recreo de la infancia argumentos para otro comienzo. Buenos Aires, Argentina: Siglo XXI editores Argentina.

Corea, C. Lewkowicz, I. (1999). ¿Se acabó la infancia? ensayo sobre la destitución de la niñez, 1171Recuperado de https://es.scribd.com/doc/212477684/COREA-LEWKOWICZ-Se-acabo-la-infancia-pdf

Espinosa Gòmez, A.M., (2013) Configuración de la subjetividad en la primera infancia en un momento 
posmoderno (Tesis de maestría inédita). Universidad Distrital Francisco José de Caldas, Bogotá,

Colombia. Recuperado de https://dialnet.unirioja.es/descarga/articulo/4814912.pdf

Giddens. A. (2007). Un mundo desbocado, los efectos de la globalización en nuestras vidas (Runaway World) En Satillana Ediciones Generales, 1 - 39. Recuperado de

http://eva.universidad.edu.uy/pluginfile.php/506145/mod resource/content/1/Giddens,\%20Anthony\%20$\% 20$ Un\%20mundo\%20desbocado.pdf

Lajarraga, H. (2012). La subjetividad del niño en la posmodernidad. Arch Argent Pediatr, 110(4), 318-322. Recuperado de: http://www.scielo.org.ar/pdf/aap/v110n4/v110n4a08.pdf

Luhmann, Niklas., (1992). Sociología del riesgo (Sociologie des Risikos), 1 -158. Recuperado de https://analisisinstitucionaluba.files.wordpress.com/2013/08/sociologia-del-riesgo-niklas-luhmann.pdf

Mancini. F., (s.f.). Riesgos sociales en sociedades complejas. Una mirada desde la sociología contemporánea. 1 - 11. Recuperado de:

http://actacientifica.servicioit.cl/biblioteca/gt/GT31/GT31 ManciniF.pdf

\section{Contenidos}

\section{Aproximaciones conceptuales}

Se abordan teóricamente las principales categorías que se desarrollan a lo largo de la investigación, entre ellas: Infancia y subjetividad política infantil, Teoría del riesgo social y Prácticas de riesgo como categoría conceptualizada por los mismo autores.

\section{Marco Metodológico}

Se describe la ruta metodológica que permitió el desarrollo del estudio

\section{Resultados}

Con el fin de comprender la incidencia que tienen las prácticas de riesgo de niños y niñas en el ámbito escolar para su proceso de construcción como sujetos políticos, se analizan los hallazgos a la luz de tres momentos: Significado de las prácticas de riesgo para niños y niñas, Condiciones del contexto que propician las prácticas de riesgo, y las Prácticas de riesgo como interrogante del orden institucional

\section{Discusión}

Con la presentación de los resultados el equipo investigador expone los principales elementos de reflexión y debate donde hay un encuadre con las aproximaciones conceptuales.

\section{Conclusiones}

De manera sintética se desarrollan las 4 principales conclusiones del estudio.

\section{Metodología}

Tipo de Investigación: Cualitativa de corte exploratorio

Población: 64 estudiantes (niños y niñas) entre los 8 y 11 años de edad de una institución educativa privada de profesión católica de la localidad de Engativá en la ciudad de Bogotá de nivel socioeconómico 3 y 4; además de dos grupos de adultos, integrados por 9 docentes y 7 padres y madres de familia de los grados cuarto y quinto de primaria de la misma institución.

Técnicas de recolección de información: cartografía social, taller creativo y grupo focal.

Registro de la información: De forma magnética a través de audios y videos los cuales fueron transcritos para dar paso al análisis de la información.

Análisis de la información: Se hizo a partir de la matriz metodológica donde se contemplan las categorías y subcategorías de análisis que derivan en los observables o indicadores como parámetros para el ejercicio en campo y la base para el análisis de la información.

Interpretación: Se agrupó en una unidad hermenéutica todas las fuentes transcritas para ordenarlas y dar 
inicio a la codificación de los segmentos. Luego de haber realizado todo el proceso de codificación de las evidencias, la fase final implicó las discusiones que surgieron entre los hallazgos generados por la codificación y las reflexiones del equipo investigador, en medio de un diálogo de saberes.

\section{Conclusiones}

Partiendo de los antecedentes del estudio, se reconoce en primer lugar que desde la investigación cualitativa hay una oportunidad para abordar la temática del riesgo desde la categoría conceptual propuesta, es decir, se invita a que el abordaje temático se amplié a la noción de prácticas de riesgo y con ello que los factores externos y el desconocimiento del sujeto no sean las únicas variables que se contemplen en este tipo de estudios, por su parte que la intencionalidad y toda la carga subjetiva de los sujetos sea contemplada.

Respecto a los hallazgos de la investigación, las prácticas de riesgo en niños y niñas se constituyen en una expresión de las formas en que configuran su subjetividad política, se reconocen como un medio en el que demuestran al sistema sus formas de ser y estar en el mundo y de allí que devengan diversas tensiones con el orden institucional, con el mundo simbólico de los adultos.

No obstante, se hace evidente que el riesgo para las infancias se configura en medio de quiebres, a través de los cuales instituyen sus comprensiones, sentidos y en general sus formas de ver y querer hacer en el mundo, pero que de manera cotidiana mantienen una relación de control o dominación por la institucionalidad, por los marcos normativos y morales (la religión elemento principal) de los cuales también tienden a reproducirse ciertos discursos y a configurarse conductas que cumplan con las expectativas del adulto.

De lo anterior, el juego y la exploración para las y los adultos constituyen en gran medida un factor incidente para las prácticas de riesgo en la infancia, atribuyéndoles un carácter negativo dados los niveles de exposición que generan, sumado a ello en un contexto en el que la sociedad posmoderna se asume como vulnerable ante los usos y amenazas de las tecnologías de la información y comunicación.

En este sentido son los adultos quienes colocan en gran parte la responsabilidad al entorno de las prácticas de riesgo que configuran sus niños y niñas, aun cuando no desconocen sus habilidades, conocimientos, intenciones y su capacidad de agencia, no se reconocen estos últimos como elementos constitutivos, por el contrario, son los niños y niñas quienes destacan sus posibilidades de reflexionar y decidir ante el riesgo, incluso sobredimensionan sus niveles de confianza respecto al autocontrol y dominación de los factores de riesgo.

\begin{tabular}{||l|l||}
\hline \hline Elaborado por: & Laura Juliana Pachón Rodríguez \\
\hline Revisado por: & Juan Carlos Garzón \\
\hline
\end{tabular}

Fecha de elaboración del Resumen:

\begin{tabular}{l|l|l|}
\hline 09 & 02 & 2017
\end{tabular}




\title{
LAS PRÁCTICAS DE RIESGO EN LA INFANCIA, UNA MIRADA DESDE LA SUBJETIVIDAD POLÍTICA
}

\section{RISK PRACTICES IN CHILDHOOD THAT SHAPE POLITICAL SUBJECTIVITY}

\author{
Juan Pablo Jiménez Montenegro ${ }^{1}$ \\ Laura Juliana Pachón Rodríguez ${ }^{2}$ \\ Marcela Ramos López ${ }^{3}$
}

\section{Resumen}

El siguiente artículo da cuenta de los resultados de la investigación realizada alrededor de las prácticas de riesgo que asumen niños y niñas en el ámbito escolar y cómo éstas influyen en la configuración de su subjetividad política, de allí que las comprensiones alrededor del riesgo, las condiciones del contexto y las formas en que se interroga el orden institucional se convierten en inquietudes específicas sobre los cuales se orienta el estudio. Conforme a ello el esquema metodológico se suscribió desde una mirada interpretativa cualitativa de corte exploratorio que permitió el reconocimiento de las relaciones entre riesgo y subjetividad política en la infancia y a partir de allí los significados y las acciones que tienen lugar no solo desde el escenario escolar sino en el marco de una sociedad posmoderna incidente en las reflexiones, intenciones, decisiones y tensiones que entre niños, niñas, adultos e instituciones se originan alrededor del tema.

Palabras clave: Infancia, riesgo, prácticas de riesgo, subjetividad política infantil, ámbito escolar.

\begin{abstract}
The following study provides the results of the research conducted on risk practices taken by boys and girls in the school environment and how these influence in shaping their political subjectivity; this is why understandings around risk, context conditions and the way the institutional order is questioned, become specific concerns on which the study is guided. According with the aforementioned, the methodology outline was endorsed from an interpretative - qualitative perspective of exploratory type that allowed recognizing the relationship between risk and political subjectivity in childhood and from there, the meaning and actions that take place not only from the school environment but within the framework of a post- modern society that affects reflections, intentions, decisions and tensions that within boys, girls, adults and institutions arise around the issue.

Key words: Childhood, risk, risk practices, child political subjectivity, school environment.

${ }^{1}$ Licenciado en Diseño Tecnológico. Universidad Pedagógica Nacional

${ }^{2}$ Trabajadora Social. Universidad Colegio de Cundinamarca. Especialista en Gerencia de Talento Humano - Universidad Sergio Arboleda

${ }^{3}$ Licenciada en Educación Infantil. Universidad Pedagógica Nacional
\end{abstract}




\section{Introducción}

La investigación que presentamos parte de los conceptos de Corea y Lewkowicz (1999) y Bustelo (2007) donde la infancia es entendida como una categoría social emancipadora que reivindica la capacidad crítica y autónoma de niños y niñas, y quienes se abren paso en escenarios donde el mundo adulto creía no tenían posibilidad de comprensión, decisión, acción y resignificación, por otra parte hablar de situaciones o conductas riesgosas en la infancia en muchos casos implicaba desvincular su capacidad de interpretación y decisión y por su parte desde la intervención social hacer abordajes que impactaran exclusivamente el contexto, desconociendo todas las posibilidades de significación que hay detrás de ellos y ellas.

Con esa mirada, el equipo investigador se ubica en el escenario escolar y da paso a una pregunta problematizadora que asume al niño y a la niña como un sujeto político que da un sentido al riesgo y a partir del cual emprende conductas que para el escenario institucional (incluyendo la familia) probablemente constituyen un peligro para su integridad física y psicosocial. De ahí que el ejercicio de investigación pretenda aproximarse a esos significados que la infancia construye alrededor de las prácticas de riesgo y que en ocasiones es el mundo adulto el que los asume por ellos y para ellos.

En este sentido, los objetivos general y específicos del estudio son respectivamente,

Comprender la incidencia que tienen las prácticas de riesgo de niños y niñas en el ámbito escolar para su proceso de construcción como sujetos políticos.

-Comprender el significado de prácticas de riesgo para niños y niñas e identificarlas dentro del ámbito escolar.

-Reconocer las condiciones del contexto que propician las prácticas de riesgo en niños y niñas en el ámbito escolar.

-Entender cómo las prácticas de riesgo interrogan el orden social de la institucionalidad.

De este modo, se sustenta la necesidad de reconocer los significados que los niños y las niñas redefinen alrededor del riesgo de tal manera que nuevas apuestas investigativas logren un hilo más fino y a su vez para que los abordajes clínicos y psicosociales que desde la prevención y la atención se hacen y seguirán haciendo, logren un mayor diálogo con las realidades de nuestras infancias y de este modo se contemplen metodologías más integradoras y participativas.

Lo propuesto anteriormente cobra sentido al reconocer que los antecedentes permitieron detectar que los estudios del mismo orden, redundan en la identificación de los factores de riesgo 
(biológicos, psicosociales, ambientales, etc) que propician conductas alrededor del pandillismo, el suicidio, la bulimia o anorexia, la violencia escolar, las relaciones sexuales sin protección, el consumo de SPA entre otros, y donde la investigación de corte cuantitativo - descriptivo cobra mucha fuerza, o en su caso, los estudios de mirada cualitativa retoman constantemente los factores y las situaciones riesgosas desde fuera de la comprensión de las o los sujetos, adicional la población objetivo para este tipo de investigaciones en su mayoría vinculan a adolescentes y jóvenes quedando rangos de menor edad por fuera de los estudios.

Lo anterior, se hace evidente en el análisis de 19 investigaciones consultadas alrededor del riesgo escolar en el contexto colombiano entre el año 2010 - 2015, de donde se rescatan algunos elementos como: apertura en los procesos de investigación social a nivel nacional frente al riesgo en la adolescencia destacando fenómenos sociales como el pandillismo, consumo de SPA y conducta suicida, el 65\% de las investigaciones vinculan las dimensiones familiar y comunitaria como factores asociados a los diferentes fenómenos que hacen parte del riesgo y un $45 \%$ trabajaron desde enfoques netamente clínicos e individualizados, lo que arrojó resultados eminentemente descriptivos y cuantitativos.

Con ese panorama se orientó un proceso metodológico con mirada cualitativa, interpretativa y de corte exploratorio, que puso en diálogo la pregunta de investigación y las reflexiones que las y los niños participantes, padres y madres de familia y docentes tenían alrededor del riesgo, de tal modo que los resultados, contrastados con los fundamentos teóricos permitieron reconocer la relación proporcional entre las prácticas de riesgo infantiles y la configuración de su subjetividad política, además de la incidencia del contexto familiar, escolar y social en la construcción de significados y de su capacidad de agencia.

Así pues, encontrará las aproximaciones conceptuales y teóricas que dan lugar al enfoque de la investigación, nuevas miradas de la infancia, su constitución como sujetos políticos y algunos planteamientos desde la sociología contemporánea alrededor del riesgo, adicional y guardando una secuencia lógica con el proceso investigativo, se sustentará su diseño metodológico, los resultados obtenidos para la institución educativa en la que se ubicó la recolección de información y finalmente las reflexiones y discusiones que se suscitaron para el equipo investigador luego del camino recorrido. 


\section{Aproximaciones conceptuales.}

\section{Infancia y Subjetividad política infantil.}

Destacar la categoría de subjetividad política en la infancia, implica para la investigación dar un sentido teórico y ético respecto a la comprensión de lo que es ser niño o niña, en este sentido se comparten las posturas de Corea y Lewkowicz (1999) y Bustelo (2007) cuando afirman que la infancia deja de ser un período de tiempo exclusivo en el desarrollo de los seres humanos y donde niños y niñas no se constituyen en seres inacabados, sino por el contrario se asumen como agentes sociales dinámicos y en constante evolución que logran poner en juego el orden social establecido en un marco de realidades y condiciones que ofrece el contexto, a partir de allí se entiende que la infancia se constituye desde las interacciones con otros, con los objetos y el ambiente en medio de la experiencia.

Dado lo anterior, hoy se habla en algunos escenarios académicos del término infancias, el cual es asociado no solo con aquella que viven niños y niñas sino que se contempla la infancia que han vivido los adultos, a ello se le suman las capacidades y formas de estar en el mundo que tiene cada sujeto, la época, condición económica, cultural y social, lo que permite configurar diferentes experiencias y por ende diversas expresiones de la infancia.

Dicha diversidad, se sitúa justamente en lo que Corea y Lewkowicz (1999) asumen como universo infantil y el cual de manera compleja es interpretado simultáneamente desde dos posiciones: la moderna y la posmoderna. La primera valora los ideales de la infancia instituidos por la sociedad de la época, mientras que la segunda se valora la experiencia actual de niños y niñas con el consumo de tecnología, cultura audiovisual, televisión, entre otros, en medio de este balance las infancias van configurando y representando sus intenciones y experiencias aun cuando se comparte la idea que "el tipo de infancia no es deducible; hay que esperarlo en la escena en que realmente se manifiesta", (Corea y Lewkowicz, 1999, p.170), en tanto que solo se pone de relieve a través de sus decisiones y acciones.

A propósito de las reflexiones que se suscitan en medio del comparativo modernidad / posmodernidad, El Recreo de la Infancia (Bustelo, 2007) muestra la infancia más allá de la categoría "sujeto de derechos", para el autor se traduce en el "quiebre legal de un orden tutelar represivo anterior"(Bustelo, 2007, p. 126), inhabilitando así toda comprensión que coloca a niños y niñas como seres necesitados de compasión, reconocidos por su inocencia, reproductores del sistema y tabulas rasas que deben ser moldeadas, pues esto conlleva a anular ciertos derechos donde su capacidad de reflexión, participación, creación, interrogación, valoración, etc, se derogan y de 
manera consecuente el análisis del concepto sigue quedando por fuera de un marco teórico asociado al cambio social (Bustelo, 2007, p. 155), es decir que mientras la construcción de teoría frente a la categoría de infancia se siga dando de manera sistemática y desarticulada con la realidad que viven niños y niñas y su importancia dentro del contexto social, no se logrará una transformación integral.

Bajo esta postura el reconocimiento de la subjetividad política en las infancias parte precisamente de las tensiones generadas entre la realidad de niños y niñas (sus condiciones, comprensiones, sensaciones, prácticas, aspiraciones, etc.) y las expectativas que la institucionalidad configura para ellos, además de proyectar transformaciones de plano social que ellos constantemente resignifican, poniendo así al sistema (instituido) en punto de quiebre. (Corea y Lewkowicz 1999)

Según los autores aparece una confrontación desde los lugares que buscan definir la realidad de la infancia, en este sentido aparecen dos perspectivas, como ya se han mencionado, "moderna y posmoderna", en la primera se invisibiliza y determina la infancia como una sola, a la cual se le atribuye toda la carga de reproducción de una sociedad ya establecida, es catalogada como el lapso en el que el niño no cuenta con espacios de participación en sus contextos pero la institucionalidad sí lo asegura como proyección futura de la sociedad moderna, por el contrario, en la posmoderna se produce una ruptura frente a la concepción y el desarrollo de la infancia, primero ya no se habla de una sola sino varias infancias ya que cada una está cargada de construcción subjetiva en la que se reconoce y valoran las posturas y las formas de ser y estar en el mundo instauradas por los niños y niñas, se aprecia más la experiencia que ellos adquieren en relación con toda la cultura audiovisual, tecnológica y de consumo a la que están expuestos, razón por la cual el tipo de subjetividad que constituyen las infancias se vuelve cada vez más difícil de dilucidar, demandando el tiempo necesario para identificar a través de las prácticas que tienen lugar en diversos escenarios sociales aquellas que pongan de manifiesto sus configuraciones subjetivas.

Así pues, desde los análisis de la posmodernidad se reconoce que para la infancia la subjetividad política es ilustrada desde criterios tanto de tensión como de evolución, puesto que es producto de las experiencias que se tejen en interacción con otros y con lo otro y que están transversalizadas por las condiciones de los diferentes contextos, lo que hace que constantemente se reconfigure el saber y ser de niños y niñas, según Hernández (2010), citado por Espinosa (2013, p. 19) la construcción subjetiva que parte de las experiencias en multiplicidad de escenarios se entiende como "autonomía vivida". Paralelamente se considera desde Martínez (2010) citado por Espinosa (2013, p. 19) que todo sujeto, en este caso las infancias, construyen su subjetividad no sólo a partir de dichas experiencias, sino de las circunstancias que lo conducen a generar prácticas específicas, por ejemplo 
el lugar que ocupa en su territorio, la accesibilidad económica, las dinámicas sociales que lo circundan y sus esfuerzos por obtener reconocimiento social, todo ello determinando tanto sus formas de ser y estar, como la forma en que es reconocido por los colectivos.

Con estas referencias, la categoría de subjetividad política infantil para el proceso de investigación se resume como un escenario que se encuentra en un proceso de configuración continua, que muta conforme se desarrollan las experiencias de vida y donde la relación con otras personas es un elemento primario, dicha configuración se logra en la medida en que el niño y la niña interpelan continuamente la realidad de la cual hacen parte y en la que constantemente se pretende avanzar por el reconocimiento social (mediado por espacios intersubjetivos y subjetivos) que garantice la posición de ellos y ellas como agentes sociales incidentes del contexto y que propician la modificación o generación de nuevas prácticas.

Entender la subjetividad política infantil es descubrir en un escenario instituido aquellos esfuerzos de los niños y niñas por ubicar sus propias posturas frente a otros actores sociales e institucionales, lo cual legitima para ellos una forma de ser y estar en el mundo ${ }^{4}$, lo que visiblemente posiciona sus propios discursos y prácticas. Con ello, la subjetividad política de las infancias se reconoce, precisamente, a partir de su carácter autónomo y crítico, donde la influencia del medio es evidente (los sucesos, los medios de consumo, las nuevas tecnologías, medios de comunicación, etc.), así como el proceso de configuración de múltiples subjetividades que se abren paso a través de las relaciones sociales y donde niños y niñas no solo producen unas interpretaciones y significados, sino que tienen además todas las capacidades y posibilidades de decidir, tomar parte o no, de demostrar su conformismo e inconformismo, de racionalizar o quizás de soñar y de demostrar que su existencia también transita por senderos de independencia, donde definen sus propios espacios y donde sus lógicas deben alternar con las de los demás sujetos.

\section{Teoría del riesgo social.}

Para el ejercicio investigativo el riesgo se incorpora como una categoría central en el desarrollo de la pregunta problematizadora y se conjuga con las reflexiones sostenidas alrededor de la subjetividad política en niños y niñas, dado que se considera que toda práctica riesgosa en la infancia incorpora sus capacidades y posibilidades para interrogar el marco social. En este sentido, las infancias se ubican en un escenario en donde se instituyen conductas que para el mundo adulto

\footnotetext{
${ }^{4}$ Para el filósofo alemán Martín Heidegger (1889-1976), quien se interesó por desarrollar investigaciones a la luz de la categoría "ser ahí o ser en el mundo", entender el concepto de ser, implica no solo el interés del sujeto por conocer sino por ubicar su lugar en el mundo.
} 
son el reflejo del peligro y las cuales posiblemente se definen como situaciones que están fuera de su capacidad de agencia.

Indudablemente existen referencias teóricas que han abordado la categoría y sus planteamientos obedecen a diversos paradigmas y enfoques, pero en éste caso es desde la sociología contemporánea que se retoman algunas propuestas, particularmente desde la teoría social del riesgo y de la cual se derivan varias corrientes o perspectivas. De entrada existen discusiones y reflexiones frente al riesgo social como un elemento estructural y natural de la vida en sociedad, sin embargo, cada enfoque reconoce características específicas frente al tema y sobre todo resaltan nuevas comprensiones respecto a la configuración social de los riesgos contemporáneos como lo denomina Mancini (2013).

En este sentido y de manera generalizada se asume el riesgo como un concepto característico de las denominadas sociedades complejas o modernas (Mancini 2013, p. 2), las discusiones teóricas coinciden en que se concibe como una construcción social e histórica y por ende su condición es indeterminada, de allí que su análisis sea complejo e implique comprensiones cercanas y actualizadas de las dinámicas sociales.

Para efectos del tema de investigación, la perspectiva que se retoma como soporte epistemológico es la que Mancini (2013) denomina corriente reflexiva en donde el riesgo es un componente propio del hombre moderno y por ende del capitalismo. Por esta línea aparecen diversos autores como Giddens (2007), Beck (1998) y Luhmann (1992) quienes en principio asumen el riesgo “como una forma temporal de racionalidad, en definitiva, como una amenaza actualizada que permite seleccionar opciones en función de decisiones específicas" (Mancini, 2013 p. 2). Para estos autores y en general para esta perspectiva el proceso racional que va de la mano con el riesgo no es una cuestión de tipo instrumental sino de orden reflexivo dado que supone aumento de opciones y por ende de las decisiones en el sujeto, adicional, tal como lo menciona Mancini citando a Luhmann (1992) el riesgo es un concepto que de manera inherente denota la "posibilidad de daños futuros por decisiones tomadas en el presente que implican cálculos temporales específicos"

Así pues, los sociólogos Beck (1998) Giddens (2007) y Luhmann (1992) son los referentes centrales para la argumentación teórica del proceso investigativo y de quienes se han seleccionado los planteamientos más destacados y afines con la pregunta problematizadora.

Se parte de las definiciones de Beck (2002) quien plantea que el riesgo no puede verse como los daños o las afectaciones producidas, es decir, que no es la destrucción física o psicológica del individuo en sí misma sino la amenaza que pueda haber hacia ellos, es por esta razón que se 
comparte la idea del riesgo como un fenómeno que emerge de una construcción social en donde el sujeto, toma parte frente a las situaciones o acciones denominadas "peligrosas" y que tienen un contenido para el orden social y donde se revela ante la posible "amenaza" la capacidad de decisión, visión y posturas ante el mundo.

En cuanto construcción social, el riesgo es definido por la misma comunidad o colectivo que produce o constituye el fenómeno, en ese sentido Beck (1998) reconoce que "es la sociedad misma la que de acuerdo a su percepción y apropiación cultural la que establece y da los marcos en los que debe constituirse el riesgo para el sujeto". Dicha relación que se teje entre el sujeto y el riesgo crea un canal de comunicación al que el autor llama "Mediación", donde a pesar del conocimiento que posee el individuo sobre los posibles "daños" que puede producir una acción o hecho, este toma la responsabilidad de afrontarlos, de allí que estos planteamientos naveguen sobre la perspectiva reflexiva donde se entiende de cierta manera que el riesgo se traduce en una alternativa de decisión para el sujeto, decisión que es producto de la tensión existente entre el sujeto (consigo mismo) y la sociedad de la que es parte, develando tanto consideraciones o significaciones individuales como colectivas en donde el riesgo representa la relación subjetiva que recoge patrones de racionalidad e irracionalidad del mismo sujeto o de los colectivos.

Cuando se habla del carácter subjetivo de los individuos frente al riesgo, se desentraña la lógica de dominio que la sociedad infunde, allí aparece Beck (1998) para explicar cómo el riesgo justamente coexiste para reconfigurar de manera incesante las formas de control que rigen el mundo contemporáneo, el riesgo social emerge allí como posibilidad de interrogación y confrontación y como dispositivo para generar incertidumbre en toda instancia social que a su vez pretende continuamente reestructurar sus formas de control, además de anticiparse y prever la amenaza.

Además de los procesos cognitivos, reflexivos y de poder que se enuncian anteriormente es propicio dar cuenta de lo que la temporalidad implica para la comprensión del riesgo, en tanto no es solo el espacio el que genera sus condiciones, así pues del pasado, el presente y el futuro el riesgo se concibe como un producto coyuntural donde el pasado se vuelve el determinante que orienta la acción del presente y futuro, adoptando este último su posición y tomando rumbo conforme a las experiencias obtenidas (Beck, 1998) Por la tanto se concibe la experiencia como un factor incidente del riesgo, constituyéndose probablemente como el punto de partida para la ideación, generación, reproducción y decisión frente a nuevas conductas riesgosas o la planeación de nuevas alternativas para asumir las mismas. 
Del lado de Luhmann (1992) el aporte frente a la comprensión sobre riesgo social parte de definirlo no como un objeto de observación si no como un concepto, es decir, lo que llega a entenderse como riesgo para un sujeto no existe antes de que éste lo haya observado, por lo tanto el riesgo se vuelve una construcción propia del observador, no una situación concreta o realidad preexistente y establecida con anterioridad. En ese orden de ideas el riesgo sería una concepción discursiva del observador más que el hecho como tal, en palabras de Luhmann (1992), “no caracteriza ningún hecho que exista con independencia de si es observado y de quién sea el observador”. (Luhmann, 1992, p. 71)

Con ello se comprende a partir de los planteamientos del autor que el riesgo no está de manera preexistente y que deriva de la nada, por el contrario parte de un tejido circunstancial que permite consolidar el concepto, de allí que al igual que Beck (1998) tampoco debe entenderse como el daño producido, ni como suceso proveniente de la naturaleza o de la acción en sí misma, ni tampoco como la incertidumbre generada o la amenaza como tal, debe entenderse como la forma en que el sujeto comprende y asume dicho "peligro", como la manera en la que además interactúa y afronta la incertidumbre.

Complementando sus postulados, el sociólogo afirma que el riesgo toma diferentes significados dependiendo de la perspectiva con la que se asocie; por un lado riesgo y seguridad y por otro riesgo y peligro. En la primera se entiende desde la carencia o ausencia total de seguridad, lo que posiblemente implica mayor o menor influencia del contexto a partir de las condiciones, situaciones o factores de riesgo que conlleva, por su parte la segunda perspectiva destaca la idea de responsabilidad que asume el sujeto, puesto que está en juego allí su capacidad de decisión y la voluntad, propuesta similar a la del Sociólogo Beck (1998) donde se destaca la noción reflexiva de todo individuo, donde la decisión siempre tiene un "carácter de riesgo".

Por consiguiente el riesgo para el sujeto se traduce en las afectaciones generadas después de haber tomado la decisión, esto deja entender sintéticamente que los riesgos producidos por un sujeto hacen referencia paralelamente a los daños que se dan como resultado de una decisión ejecutada (que tiene un carácter previo de comprensión y reflexión) y que no se hubieran manifestado en caso de que la decisión hubiera sido distinta. Lo cual Luhmann (1992) precisa un poco más, refiriéndose al riesgo como algo imputable al sujeto, a sus concepciones, a su forma de sentir y pensar en relación a otros y con los otros, convirtiendo al peligro como la simple amenaza que proviene del exterior pero que atraviesa su subjetividad para así generar o no el daño. 
Como último referente en el desarrollo conceptual del proceso, se destaca a Giddens (2007) quien plantea la noción de riesgo a partir de la disponibilidad de circunstancias, de "probabilidades e incertidumbres“ que hacen parte de la cotidianidad del sujeto, es decir, éste se encuentra permanentemente navegando en aguas desconocidas." (Giddens, 2007, p.36). Dicha noción genera, en coherencia con los análisis del autor, una constante preocupación de la sociedad contemporánea por intervenir y controlar todas aquellas posibilidades en las que a futuro puede estar expuesto el sujeto, utilizando como escenario de actuación el presente y el ahora para intentar mitigar, prevenir y por su puesto predecir dichas tentativas de riesgo.

De este modo el riesgo se asume como una extensión futura propia del sujeto que revela una intención de fracturar el pasado y todo aquello que genere un sentido de inconformidad en él, colocándose de este modo en tensión constante con la sociedad y las dinámicas sociales establecidas, traduciendo al riesgo, según Giddens (2007), en una herramienta social que el individuo usa para dominar o regular las condiciones que determinan su propio futuro, reemplazando así la idea que los sucesos son productos del azar, de la naturaleza, del destino o decreto divino, por la premisa que todo suceso es producto de las sensaciones, el deseo, el interés, y la decisión de los sujetos, decisión que implica posiciones individuales, que según el autor hacen perder de vista el impacto que esta conlleva para los otros y el contexto.

Precisamente al vincular la noción del deseo, se reconoce por parte de Giddens (2007) que la aceptación del riesgo en el sujeto genera una condición de excitación, miedo, aventura, deseo y satisfacción, las cuales están mediadas por sensaciones diversas que varían según el "tipo" de riesgo que se enfrenta, conforme a ello el sociólogo propone la clasificación de riesgos exteriores y riesgos manufacturados, los primeros son aquellos producidos por la naturaleza, la tradición, el contexto y que afectan al sujeto de manera espontánea sin prever la causalidad u origen de dicho riesgo, por el contrario el segundo tipo facilita la determinación de causas, pero el sujeto carece de experiencia y conocimiento para afrontarlos pese a que algunas veces es el productor de estos mismos y tiende a volverlos repetitivos, lo cual indica que los riesgos manufacturados pueden ser sucesos, prácticas o circunstancias cíclicas que afectan de la misma forma en el transcurso del tiempo al sujeto y a la sociedad.

Para finalizar, se rescata de los análisis del autor la idea que pone al sujeto y a los colectivos como responsables a la hora de "afrontar" todas aquellas situaciones que conllevan incertidumbre y que son propias y conscientes para la sociedad moderna, dicha responsabilidad debe hacer parte del inconformismo que asumen ante la opresión del escenario contemporáneo y que les invita a luchar 
por un sentido de libertad donde hay posibilidades de transformación y de privilegiar su lugar en el mundo.

Con estas consideraciones desde la sociología, es probable homologar la idea que el riesgo social para las infancias se pueda interpretar desde la toda la carga subjetiva que le impregnan a sus experiencias de vida, todo suceso atado al riesgo posiblemente para niños y niñas se vincula a una emergencia reflexiva que pone de manifiesto su visión del mundo, las construcciones colectivas que lo median, las tensiones consigo mismo y las decisiones que reflejan su idea de pasado y su intención de futuro, son estos quizá elementos destacados a la hora de analizar el riesgo desde el comportamiento infantil, además de otras premisas centrales que se rescatan de los tres autores:

-El riesgo siempre tiene un significado para la institucionalidad y de allí que la infancia pone en juego su subjetividad cuando toma decisiones frente al mismo.

-El sistema promueve un concepto de riesgo para la infancia y de allí que provoque la incertidumbre pero también genere las formas de control.

-El riesgo visto desde las disposiciones y condiciones del contexto, pero también desde la voluntad y la capacidad de agencia de los niños y niñas.

-Las experiencias como un factor incidente en la generación o reproducción de las conductas riesgosas.

-El riesgo para la infancia puede traducirse en un instrumento útil para la ruptura de un pasado que genera inconformismo, pero que también propicia el control de sus condiciones futuras.

\section{Prácticas de riesgo}

Dado que los diferentes estudios rescatan de manera independiente términos como factores de riesgo, conductas de riesgo y situaciones de riesgo, en este estudio se pretende dar una discusión desde una categoría que articule las definiciones que de allí subyacen y que busca ser coherente con los planteamientos alrededor de la teoría del riesgo desde la sociología contemporánea.

En ese sentido el Centro de Información y Educación para la Prevención del Abuso de Drogas (CEDRO) del Perú en su módulo Conductas de Riesgo Convencionales contiene una referencia de lo que conceptualmente suele manejarse cuando se investiga o interviene el riesgo en población juvenil, de tal modo que aquí se hace la cita textual de las tres categorías que para efectos de la investigación no quieren ser individualizadas. 
"Factores de riesgo

Aquellos elementos que tienen una gran posibilidad de originar o asociarse al desencadenamiento de un hecho indeseable, o de una mayor posibilidad de enfermar o morir, pueden ser la causa de un daño o actuar como moduladores del mismo si influyen en él, un ejemplo claro podrían ser el alcohol y la conducción.

Situación de riesgo

Aquellas circunstancias que ofrecen un riesgo a toda la comunidad o grupo social, por ejemplo, permisividad en el uso de drogas; las exigencias que se imponen a la práctica de determinados deportes, o excesivo culto a la imagen corporal.

Conducta de riesgo

Se define como las actuaciones repetidas y fuera de determinados límites, que pueden desviar o comprometer el desarrollo psicosocial normal durante la infancia o la adolescencia, con repercusiones perjudiciales para la vida actual o futura. El adolescente sin experiencia, o con ésta de forma muy limitada, se compromete en conductas destructivas, sin conocer los riesgos a corto y largo plazo.” (Obregón, s.f)

Con estas claridades el ejercicio investigativo propuesto contempla una categoría más amplia y que además está en línea con la postura epistemológica que defiende la capacidad reflexiva y de decisión de las y los sujetos, en este caso, de niños y niñas y a partir del cual el riesgo tiene otras formas de configuración que no son atravesadas exclusivamente por el dominio del contexto, la ingenuidad o el desconocimiento del agente.

De esta manera se entienden las prácticas de riesgo como un conjunto de acciones que derivan de las construcciones sociales, cuentan con un carácter intencional propio y las cuales pretenden configurar y dar sentido a las formas en que una realidad es interpretada, asumiendo con ello la posibilidad de afectar el "orden" establecido por la institucionalidad en un momento determinado.

En este sentido, no sólo el entorno o el desconocimiento del mismo es lo que dispone una práctica de riesgo, por su parte existen elementos adicionales que contribuyen a su configuración, entre ellos se encuentran, la acción en sí misma como producto del intercambio subjetivo, las relaciones de poder, los saberes, la capacidad reflexiva y de decisión, las intencionalidades, los roles, la cultura y los límites físicos y sociales, con ello se pretende ampliar el concepto de conducta de riesgo, debido a que el carácter subjetivo e intersubjetivo que implica toda decisión frente al riesgo ubica al sujeto en otro lugar, reconociendo que es él mismo o ella misma quien contribuye en su configuración y manifiesta sus propias comprensiones. 
Con esta propuesta conceptual se busca que las reflexiones alrededor del riesgo social rescaten las comprensiones desde los factores o condiciones que propicia el contexto, así como las posibilidades reflexivas y decisión que conjuga el sujeto, donde la intencionalidad y la alteración que busca dar a su tiempo y espacio es un elemento trascendente en este tipo de prácticas y que no debe desconocerse, en suma, hablar de prácticas de riesgo implica reconocer que el riesgo no es puramente contingente si no que tiene una dimensión subjetiva y cultural.

\section{Marco metodológico}

Este trabajo se inscribe en el paradigma interpretativo y su carácter es de orden cualitativo y exploratorio, este último dado el interés de examinar y descubrir nuevas posibilidades en un tema poco abordado, como lo afirma Hernández, Fernández y Baptista (2010), un tipo de investigación que se convierte en un camino de emergencia para el desarrollo de nuevos estudios, (Hernández, Fernández y Baptista 2010, p. 58)

Para el desarrollo del proceso se trabajó de manera central con 64 estudiantes (niños y niñas) entre los 8 y 11 años de edad de una institución educativa privada de profesión católica de la localidad de Engativá en la ciudad de Bogotá de nivel socioeconómico 3 y 4; además de dos grupos de adultos, integrados por 9 docentes y 7 padres y madres de familia de los grados cuarto y quinto de primaria de la misma institución.

Para el trabajo de campo con los niños y las niñas se emplearon dos técnicas de recolección de información: La primera fue inspirada en la cartografía social, la cual consistió en diseñar el mapa del colegio donde a través de convenciones se pudieran relacionar los lugares de agrado y desagrado teniendo en cuenta las formas de interacción que tejen en la institución educativa. La segunda parte de un taller creativo en el que a partir de imágenes relacionadas con el riesgo (selección previa por parte del equipo investigador), niños y niñas pudieran construir un mural en el que se recrearan historias y significados, relacionando las imágenes entre sí o asociándolas con su propia experiencia.

Con estas dos técnicas se plantearon tres intervenciones (incluyendo prueba piloto) con los tres cursos que respectivamente se seleccionaron para el proceso de investigación, cada espacio de trabajo tuvo una duración de tres horas, en el que la prueba piloto inició con el ejercicio de cartografía social y luego se procedió con el taller creativo. En las siguientes dos intervenciones se invirtió el orden de las técnicas dado el nivel de disposición de los niños y las niñas.

Posteriormente en el trabajo con adultos, se definieron dos grupos focales, docentes y padres y madres de familia, respectivamente, con quienes se abordaron preguntas que partían de sus 
recuerdos de infancia y sus experiencias alrededor del riesgo, lo que involucraba además su rol paterno y materno, las relaciones con la institución educativa y en general sus comprensiones frentes a las prácticas de riesgo. Para ello se diseñó previamente una guía de preguntas que facilitara la conducción del ejercicio. De esta manera el total de la información recolectada a partir de las diferentes técnicas, se registró de forma magnética a través de audios y videos los cuales fueron transcritos para dar paso al análisis de la información.

De manera sucesiva para el análisis de la información se partió de la matriz metodológica donde se contemplan las categorías y subcategorías de análisis que derivan en los observables o indicadores como parámetros para el ejercicio en campo y la base para el análisis de la información.

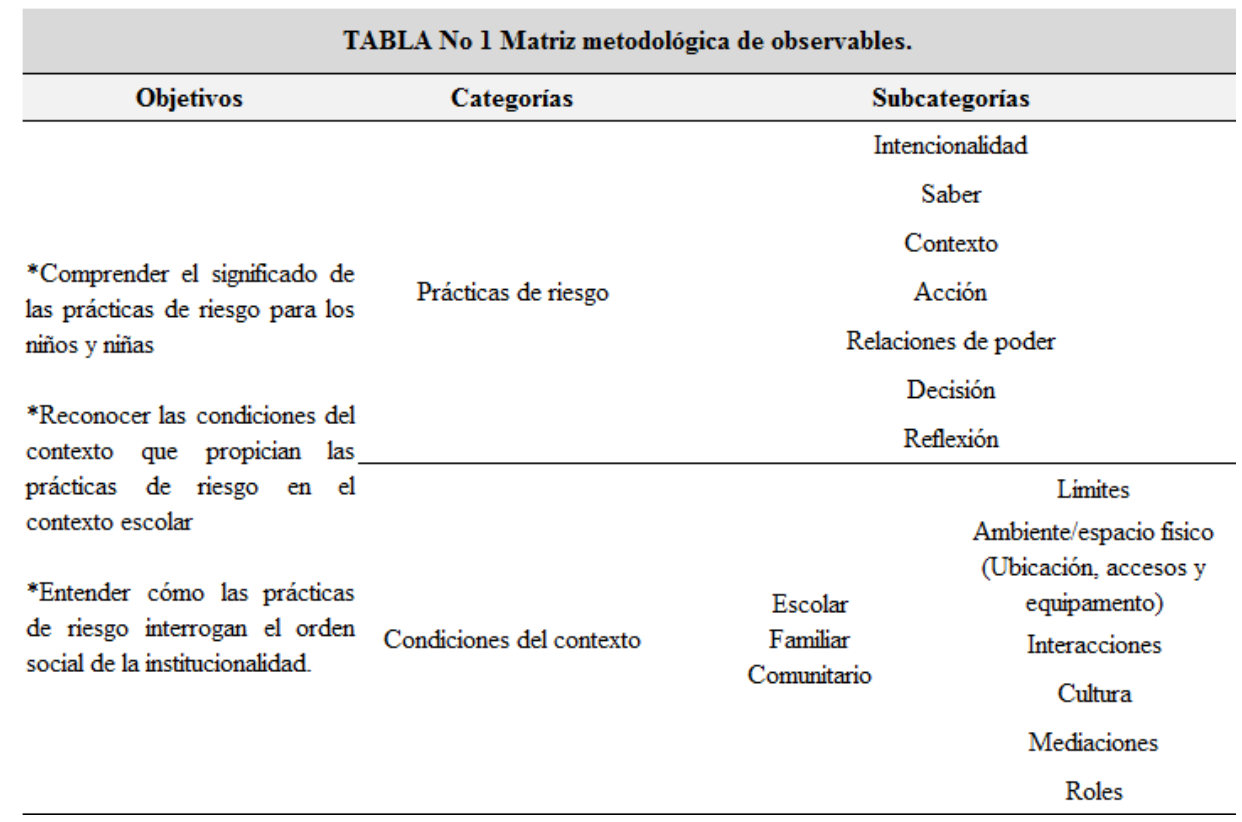

En la interpretación de los datos fue importante agrupar en una unidad hermenéutica todas las fuentes transcritas para ordenarlas y dar inicio a la codificación de los segmentos. En un primer momento la información fue codificada a partir de las subcategorías establecidas en la matriz metodológica con el objeto de clasificar la información; en el segundo nivel de codificación se seleccionaron los segmentos de cada subcategoría y se realizó un análisis de contenido desde el segmento en relación con la pregunta, los objetivos y el marco teórico con el propósito de construir códigos que mostraran los avances de la investigación en cuanto a construcción teórica, y por último la codificación axial que retoma los códigos de segundo nivel y los agrupa conforme a criterios de similitud; estos códigos axiales indican los aportes conceptuales frente al tema de la investigación, y son los que ponen sobre la mesa recomendaciones para nuevos procesos de investigación. 
Luego de haber realizado todo el proceso de codificación de las evidencias, la fase final implicó las discusiones que surgieron entre los hallazgos generados por la codificación y las reflexiones del equipo investigador, en medio de un diálogo de saberes. Finalmente la presentación de los resultados que a través del estudio se dieron y que aportan en construcción académica al concepto de "prácticas de riesgo".

\section{Resultados}

Con el fin de comprender la incidencia que tienen las prácticas de riesgo de niños y niñas en el ámbito escolar para su proceso de construcción como sujetos políticos, se analizan los hallazgos a la luz de tres momentos: Significado de las prácticas de riesgo para niños y niñas, Condiciones del contexto que propician las prácticas de riesgo, y las Prácticas de riesgo como interrogante del orden institucional.

\section{Significado de las prácticas de riesgo para niños y niñas.}

En este apartado se presentan los resultados a partir de tres subcategorías como producto del análisis de la información: La producción del sentido del riesgo desde el sujeto, La definición del riesgo desde el discurso del adulto y El riesgo como elemento de identidad para la infancia, a través de ellas se desarrollan las interpretaciones logradas en las definiciones que las y los niños construyen alrededor del concepto del riesgo.

\section{El sujeto produce el sentido del riesgo.}

De manera explícita niños y niñas definen el riesgo a través de las relaciones que éste implica con condiciones de peligro o amenaza (una condición negativa permanente), todo hecho en el que esté expuesta su integridad o la de los demás, reconociendo el carácter subjetivo que éste requiere al emerger del ser humano un proceso reflexivo, de decisión y acción.

I: para ti ¿qué es el riesgo?

Nñ: es como una forma de llamarlo como peligro, porque pues hay diferentes ejemplos, la cual nos puede llevar a medidas extremas o a decisiones mal tomadas, puede bajar nuestra autoestima, sentimientos... nos gusta expresarnos de una manera diferente y por eso nos van a tratar de otra manera y podemos tomar como malas decisiones, por ejemplo robar, matar... cosas así $(\ldots)$

Nñ: Pero sí es fácil decir... lo que no es fácil es actuar, porque a veces las tentaciones nos pueden ganar.

I: ¿Qué es una tentación a todas estas? 
Nñ: Una tentación es algo que nosotros queremos pero no tenemos.

I: ¿Y puede estar amarrada al riesgo?

Nñ: Sí porque uno podría tener la tentación de consumir drogas o cigarrillo o bebidas alcohólicas.

Las comprensiones que las infancias tejen alrededor del riesgo guardan relación directa con aspectos de tipo socio/afectivo, derivándose de ellos los grados de exposición o vulnerabilidad en los que un sujeto puede verse envuelto, en este sentido, los niños y niñas reconocen como efecto la configuración de algunas prácticas de riesgo: consumo de sustancias psicoactivas, conducta suicida, hostigamiento escolar y relaciones sexuales sin protección. Dichas prácticas son cotidianas en su macrocontexto y más cercanas a sujetos de mayor edad (adolescente y joven), poniéndose así en una distancia relativa frente a la decisión de participación o consecución de las mismas.

Nñ: (...) El riesgo que veo es que pueda llegar a tener una muerte por la soledad y la tristeza, ya que varía gente se ha muerto por la soledad.

Nñ: (...) el riesgo de las drogas es que la gente, los que no controlan bien sus emociones, piensan que las drogas es para sentirse mejor, los ayuda a sentir mejor, pero básicamente ellos mismos se están arruinando por dentro (...) después de un tiempo ellos se vuelven tan adictos que ya no tienen otra opción que suicidarse.

Las prácticas de riesgo para niños y niñas son entendidas desde la posibilidad de trasgresión a la legalidad o al marco moral que determina el contexto y por ende, es desde allí que se autoimponen límites para ejecutarlas, es decir, que no se llevan a cabo dados los juicios que infringe el sistema, más no por que consideren que son incapaces de agenciarlas.

Nñ: O sea yo me tomaría una, pero de resto nada más.

I: ¿Y si nos queda gustando y me tomo otra y otra?

Nñ: ¡Uy no!, ahí no... con todo lo que nos han dicho los policías (...)

Por su parte, el riesgo aunque es entendido desde sus posibilidades de decisión y acción, los niños y niñas desarrollan definiciones y narraciones del concepto más desde el papel de espectador, es decir, desde la experiencia del otro y no la propia, como si el riesgo no tuviera cabida en su historia de vida, y por su parte se destaca el imaginario que siempre este tipo de prácticas les permitirá la evitación o el control. 
I: Y tú ¿crees que eso es un riesgo?

Nñ: Sí porque las redes sociales, cualquiera le puede decir a uno... hola... vernos en cualquier parte y pues le pueden hacer a uno cosas malas y pues eso es un riesgo.

I: ¿Y tú has estado en redes sociales?

Nñ: sí, pero casi nunca las utilizo y a todo le tengo seguridad, entonces, pues no.

También es definida la práctica de riesgo desde la amenaza y la sujeción que el otro imprime y que obligan a la ejecución de conductas riesgosas, ello para los niños y niñas se asume no solo como acto de transgresión, sino como un factor de riesgo en sí mismo, de allí que la infancia se autodefina como una categoría social vulnerable, con un carácter de exposición permanente frente a los riesgos que pone el contexto, y que desde la investigación se entiende como un elemento que conlleva a una expropiación de su subjetividad y a un sentimiento de fractura ante el goce de ser niño.

Nñ:(...) Para mí eso sí sería una situación de riesgo, que lo estén obligando y obligando a toda hora que haga alguna cosa mala y también que uno quiera hacerlo y lo obliguen, ya lo amenazan con la mamá o con los familiares, eso sí está como situación de riesgo.

Por último, se rescata otro aspecto que dispone una práctica de riesgo y que para el caso de niños y niñas ocupa un lugar importante en medio de sus relaciones sociales, esta se configura en circunstancias determinadas al tomar decisiones que exponen la integridad física o psicosocial del otro cercano, es decir, para la infancia existe un temor de poner en peligro a quienes se ubican dentro de su círculo afectivo, debido a la ausencia de procesos reflexivos o el error en la toma de decisiones.

Nñ: o sea... que... que hay que tener cuidado en lo que uno dice, sobre sus papás o algo así porque...o información que da uno de más... porque uno puede...

I: ¡Ahhh! Con las personas ajenas

Nñ: ¡Aja! Porque uno puede dar más peligros...

\section{Definición del riesgo desde el discurso del adulto.}

Dado el carácter persuasivo y de sujeción que el adulto sostiene en los procesos de interacción con la infancia, los niños y las niñas ponen en evidencia aquellas comprensiones alrededor del riesgo que emergen de la reproducción de ciertos discursos, por ejemplo, aquellas en las que se sugiere establecer límites y guardar cierta distancia en las relaciones sociales como un factor protector. 
En este contexto, la infancia concibe los riesgos exteriores desde las posibilidades de interacción o no que ellos mismos generan con otros, esos otros que no están dentro de un círculo de confianza y en esa medida quisieran determinar su conducta, incluyendo el uso de dispositivos como las Tic's .

Nñ: Mi mamá siempre me ha dicho que pues uno, no hay que agregar a las personas que uno no conoce (...) los que no conoces mucho no hay que agregarlos (...) yo pienso que eso es para hacerte un mal o para hacerte cualquier cosa que tu no quieras (...)

Padre: (...) sí es cierto, uno conoce sus vecinos y todo, pero ¿hasta dónde los conocemos?, ¿hasta dónde conocemos a nuestros vecinos?... entonces yo, no falta, sale una niña y le pegan un jalón...porque después que se perdió una niña pero nadie la vio salir...

Por su parte, la infancia identifica prácticas riesgosas las cuales están configuradas no por la práctica en sí misma, sino por la condición de exceso que la reviste, es decir, que aunque hay ciertos comportamientos que para los marcos morales tienen un carácter perjudicial, han venido siendo naturalizados por la sociedad contemporánea y lo que determina su condición de riesgo o no, es el hecho que tal conducta desborde el "limite" permitido.

I: Entonces si es divertido, ¿no será que cuando seas grande si consumes cerveza?

Nñ: Sí, yo creo que tal vez sí consuma.

I: O sea alcohol normal ¿y drogas?

Nñ: No, esas si no.

En la medida que el sistema social dispone los ideales de sujeto, la infancia tiende a obviar riesgos tácitos que tradicionalmente se han constituido en amenaza para su desarrollo biopsicosocial, tanto así que asumen decisiones que implican prácticas riesgosas con tal de lograr el prototipo de ser humano que se espera.

Con esta interpretación, lo que la infancia traduce como riesgo, en momentos va siendo alienado con las dinámicas que el mismo sistema socio-económico plantea, invisibilizando factores de riesgo que subyacen paralelamente cuando priorizan la o el ciudadano ideal.

I: ¿Crees que ella quedó embarazada por decisión propia?

Nñ1: Sí porque ella pudo haberle puesto fin desde un principio... digamos eso no va a pasar y punto, se acabó, entonces pudo haber evitado (...)

Nñ2: O también quiso abortar (...) 
Los riesgos que involucran ciertos usos y efectos sobre el cuerpo significan para la infancia prácticas que transgreden lo que la sociedad del disciplinamiento bajo un esquema moral ha definido, en ese sentido, las practicas riesgosas para los niños y niñas se ven configuradas al afectar lo corporal tanto de manera temporal como permanente, en esta medida alterar la estética o los estados de conciencia se convierte para ellos en patrones de normalidad o anormalidad siendo esta última un criterio para asumir el riesgo.

Docente: (...) por ejemplo traen a la policía quienes son los que le hacen a ellos talleres (...) yo veo que el colegio busca como que los niños eviten ese tipo de riesgo más que todo desde la contaminación de su cuerpo, porque pues aquí obviamente esta es una comunidad religiosa $(\ldots)$

Nñ: malo, porque pueden dañar los pulmones pueden dañar el cuerpo de uno y pues la idea es cuidarlo, o sea a mí no me parece genial de que algunos niños se hagan tatuajes, porque pues Dios nos dio el cuerpo que es, yo respeto mi cuerpo, pero ellos no lo hacen.

\section{El riesgo como elemento de identidad para la infancia.}

Dentro de los significados que niños y niñas destacan alrededor del riesgo aparece la identidad como un elemento subyacente, en la medida que esta se vincula a las posibilidades o no de ser y estar en el mundo, expresado a través del cuerpo y de lo que implica ser niños y niñas, en esta medida las infancias comprenden las prácticas de riesgo desde las oportunidades y alcances que lo corporal va rindiendo en cada etapa del desarrollo, es decir, que el riesgo se asume como un concepto variable al que se le va otorgando significado en la medida que el transcurrir vital avanza y por ende el hecho de crecer representa una ocasión para favorecer nuevas prácticas.

$\mathrm{I}: ¿$ Crees que cuando grande si vas a consumir alcohol?

Nñ: Sí yo creo que tal vez sí consuma para ir a rumbear.

Las infancias estiman que su condición innata de gozar, jugar, divertirse, fantasear implica dar cabida al riesgo, hay una connotación permanente de peligro cuando al ser niño o niña las posibilidades del disfrute desbordan las condiciones de seguridad.

Mamá 2: (...) en el barrio hay una bajadita así y es que una amiga tenía una monareta, sí que uno no frenaba con... si no frenando hacia atrás, resulta que esa bicicleta se le dañó, esa era la bicicleta del barrio y uno tenía que frenarla con un zapato atrás y uno en esa bajadita, o sea era la felicidad. 
Por su parte, las lecturas que se hacen desde el uso del cuerpo también cobran sentido en niños y niñas cuando se convierte en instrumento de las prácticas de riesgo para representar lo que se calla y en ocasiones captar la atención de los otros, aquí la identidad asociada con el uso del cuerpo supera los límites de la norma.

Nñ: Ella el año pasado cogió unas tijeras filosas y casi se las mete en el cuerpo

I: ¿Estaba solita?

Nñ: No, estábamos en grupo, sino que estábamos estudiando.

A su vez se identifica la capacidad de los niños y niñas para invisibilizar su propia integridad cuando también está expuesta la del otro cercano, usualmente aquellas personas que hacen parte de su microcontexto (la familia) y en ese sentido hacen explicita su intención de contener cualquier riesgo que emerja del entorno.

Nñ: una vez mi papá, varias veces se han chocado los carros y pues él tiene una pistola, pues porque él es guardaespaldas, entonces él tiene que llevarla, entonces él la llevó y le metió tres tiros ahí a las llantas y pues me dio mucho miedo que la policía llegara y se lo llevara.

Finalmente, el riesgo como elemento de identidad implica para las infancias una relación directa con los "mandatos divinos", los niños y niñas dentro de un marco religioso explicito condicionan las practicas riesgosas a las prescripciones que desde lo espiritual se forma en ellos y ellas, hay un cuidado permanente por fortalecer sus convicciones con el cumplimiento del deber moral y por ende con escapar a lo perverso.

I: ¿Tu qué piensas de eso?

Nñ: Pues que es muy malo para la vida y pues que Dios nos perdona todo lo que hacemos, entonces no tenemos que dañar el cuerpo y porque Dios murió en la cruz por nuestra culpa, entonces tenemos que ayudarlo también a él.

\section{Condiciones del contexto que propician las prácticas de riesgo.}

En este apartado se presentan los resultados desde tres subcategorías: Distancia entre el mundo simbólico del niño y el adulto, El carácter innato del riesgo atribuido a la infancia y El riesgo como 
producto de tensiones entre infancias, a partir de ahí se desarrollan interpretaciones asociadas con las condiciones del contexto

\section{Distancia entre el mundo simbólico del niño y el del adulto.}

En cada uno de los contextos se establecen dinámicas propias que se materializan en las interacciones que niños y niñas tienen en relación con sus pares y el mundo adulto, allí emerge una de las tensiones más relevantes, donde las dificultades en el uso del lenguaje aumenta la distancia entre sus mundos simbólicos, las formas de trasferir sus propias comprensiones queda imposibilitada ante una comunicación impertinente o ausente.

Se entiende que los mundos simbólicos de las y los niños y los adultos por naturaleza no lograrán un engranaje perfecto, siempre serán particulares, aumentando de esta manera las resistencias y la explosión de mayores fenómenos asociados al riesgo, lo que significa a su vez la necesidad de ubicar mecanismos que favorezcan de alguna manera su proximidad.

Docente: En el tema referente al seguimiento de instrucciones nosotros como adultos no sabemos dar instrucciones claras y concisas para con los niños...entonces digamos que ellos al no entender eso...digamos que ese puede ser un patrón importante a la hora de realizar prácticas riesgosas, no escuchar, pero no porque no sepan escuchar sino porque no se da con claridad la instrucción.

Las distancias de estos mundos cobran mayor sentido al poner en evidencia la capacidad del adulto para configurar la subjetividad infantil desde sus propias experiencias ante el riesgo, allí emergen sus temores y son transferidos en sus relaciones con los niños y niñas, sus estados constantes de alerta condicionan las posibilidades de la infancia. Frente a lo anterior, aumentan los temores del adulto respecto a una infancia que va descubriendo y desarrollando su habilidad en la toma de decisiones, va desplegando su carácter de independencia y autonomía descolocando así su rol tradicional de cuidador y protector.

Mamá 1: (...) Mi hijo: <<Yo quiero montar solo>>, entonces ahí yo me pasé porque dije no, un caballo ya es más alto y me da miedo que de pronto una fractura o algo, (...) yo pensaba <<aquí si no lo dejo solo >> dije <<no, no, no >> . . entonces yo le dije: $<<$ Mire, voy a montar yo y después monta usted a ver como es >>, pero yo era de pura fuerte porque a mí los caballos no me gustan, nunca me han gustado (... ) me soltó por allá encima de un matorral de esas fresitas pequeñitas, ¡Dios mío!, entonces yo de ahí le tengo miedo y como yo le tengo miedo, entonces le hago dar miedo a los míos (...) 
De la tensión explícita entre estos dos mundos simbólicos, emerge el castigo como un dispositivo represor y moldeador de la subjetividad en niños y niñas, aquí el riesgo al no concebirse como una experiencia posible para la infancia, impulsa al adulto a buscar el mecanismo más rápido para poner límites y generar control, en esta medida lo punitivo representa lo que el adulto quiere del otro, pero no sabe cómo demandarlo a través de otros lenguajes.

Docente: (...) de pronto los niveles de tolerancia a la frustración que pueden llegar a tener los niños y eso lo adoptan a partir del modelo que imprimen los papás y ahí va el siguiente factor ¿Cómo castigan ese tipo de cosas?, si a mí me castigan de cierta forma, pues puedo tener una orientación al logro parcial muy alta o muy baja.

\section{El carácter innato del riesgo atribuido a la infancia.}

Para las prácticas de riesgo en la infancia el contexto es entendido como el componente principal, dada la condición de vulnerabilidad que implica el ser niño o niña, para el mundo adulto, la infancia significa en la mayoría de ocasiones una expresión tacita de ingenuidad e impulsividad cosificando su posición frente a una situación riesgosa, en esta medida, lo externo siempre va a configurarse como la oportunidad para el peligro, va a mantener una relación infinita entre las y los niños Vs la amenaza.

En este sentido lo externo implica los medios de comunicación, las nuevas tecnologías, el otro, los territorios inseguros y la comunidad como un agente indiferente e inhibidor de las relaciones de confianza.

Mamá 1: (...) mi hijo es un niño todavía muy inocente, él es muy inocente en ciertas cosas...

Mamá 4: (...) bloquear las palabras asociadas ¿sí?, ahí Google tiene una opción para bloquear palabras... sexo... bueno, la lista que uno crea útil, para poder estar uno más tranquilo, (...) a veces cuando los computadores les entra virus, sin estar buscando nada inmediatamente le entra a páginas porno y abren, (...) por ejemplo tu nene en el celular, pues es muy sencillo... o sea, él puede que no sepa, pero seguro hay otro que sabe, él que sabe le enseña $(\ldots)$

Tradicionalmente el juego se ha constituido como un elemento innato en la infancia a partir del cual se desborda el sentido del riesgo, es en medio de la exploración, el movimiento y la curiosidad 
por ir más allá, que los niños y las niñas se ven envueltos en circunstancias de riesgo no

premeditadas, es desde la imaginación, la fantasía y la diversión donde las practicas riesgosas se ven encapsuladas y los procesos reflexivos no logran tomar forma.

En esta oportunidad tanto la mirada adulta como la de los propios niños y niñas, reconoce que el juego diluye las posibilidades de reflexión, análisis y anticipación, pareciese que se mantiene un mundo paralelo para la infancia donde el riesgo entra a formar parte de la escena.

Docente: ... hay que tener en cuenta lo esperable y natural en la exploración de un niño, un niño no ha desarrollado estrategias cognitivas para evaluar el riesgo, entonces para él simplemente va a ser un juego, (...) bueno no hay que psicopatologizar lo que consideramos como un riesgo, sino es una exploración natural y esperable en los niños...

De lo anterior, aparece la curiosidad como un estigma frente al riesgo, aun cuando se reconoce su carácter innato en los procesos de desarrollo de la infancia, el mundo adulto e incluso los mismos niños y niñas la citan como un elemento predisponente, hay en ella una condición de perversión y en este sentido reviste de manera permanente una noción maligna y adversa.

Nñ: Pues hay niños que dicen que nunca harán eso, pero terminan haciéndolo porque después la curiosidad les gana y terminan en la adicción a la droga... al cigarrillo (...)

Docente: (...) una práctica de riesgo son las TIC'S ahora los chicos se están metiendo a diferentes redes sociales a escondidas hasta de los padres por simplemente la curiosidad, la curiosidad es una factor de riesgo también (...)

En este orden de ideas, la exploración al ser innata en la infancia genera una serie de prohibiciones por un intento de prevenir prácticas de riesgo, sin embargo, el niño construye una simbiosis entre la prohibición impuesta por el adulto o el contexto y su curiosidad, lo cual se hace interesante para el niño pues es la posibilidad de avanzar y alterar el orden en el mundo simbólico del adulto.

Mamá: Entre más se prohíbe, más curiosidad les causa... Lo que te digo, yo puedo controlar en mi casa, pero el niño sale y (...) 
De otro lado, el riesgo en la infancia cobra sentido al configurarse desde las formas de canalización que ellos y ellas disponen ante situaciones de quiebre emocional, es decir, los niños y las niñas a través de otros lenguajes buscan descargar las tensiones emocionales originadas por el contexto, lo que en ocasiones deriva en una práctica de riesgo.

Docente: el niño no lo logra procesar, por ejemplo el caso de una separación de padres, el niño no logra procesar eso, no lo puede expresar abiertamente, no lo entiende como sentimiento, es decir no puede utilizar su inteligencia emocional efectivamente por lo tanto el niño empieza a orinarse en la cama, ser agresivo en el colegio, el niño empieza a tener espacios lapsos de... donde se va. Ese tipo de situaciones lo ponen en riesgo (...)

\section{El riesgo como producto de tensiones entre infancias.}

Como se ha mencionado anteriormente, entre la infancia moderna y posmoderna existe una gran tensión, pues en medio de ellas se tejen una serie de dinámicas sociales y subjetividades que hacen que las relaciones entre los actores tomen tintes de dominación o sujeción que propician prácticas de riesgo, igualmente en las relaciones que se establecen entre pares.

La mayoría de las tensiones entre las infancias se da en la esfera del juego, por su característica innata permite que los niños y las niñas desplieguen toda su subjetividad y construyan desde la emocionalidad otras formas de relación:

Docente: (...) la aceptación, digamos que los vínculos en los niños a partir de ciertas etapas de desarrollo se da a través del juego, si yo no lo hago bien pues puede ser una práctica riesgosa porque no me están aceptando dentro de ese círculo de amigos, entonces digamos que yo lo podría englobar de forma soberana en relación con la aceptación socio afectiva con pares y con adultos.

En este escenario, para el niño ser aceptado por sus pares se convierte en un factor determinante, la búsqueda de compañía y reconocimiento hace que niños y niñas asuman silenciosamente prácticas de riesgo que se traducen en hostigamiento escolar, consumo de SPA, conductas suicidas, entre otras, o el sometimiento a las mismas sin prever las consecuencias de tipo afectivo, físico y/o psicológico de estas acciones 
I: y aquí en el colegio ¿tú has visto prácticas de esas?

Nñ: Si... por ejemplo en mi salón, un niño, un niño le decían gordo, "porque él es gordo" ¿sí? entonces le dicen... gordo, choncho, le dicen cosas así, pero el... no le importa, el, sigue su vida sin ponerles cuidado a ellos, y así.

Es así que el sometimiento se convierte en un riesgo latente para la infancia, los mismos niños y niñas se vulneran los unos a los otros por mantener el control sobre las situaciones que viven y sobre el contexto y así configurar un mecanismo de defensa frente al mismo riesgo.

I: entonces ¿vivimos en el riesgo?

Nñ: si...

I: ¿Cómo vivimos con el riesgo? O ¿Cómo lo ven ustedes?

Nñ: yo lo identifico con las... cuando nos pegan, cuando nos... maltratan, cuando nos... obligan hacer cualquier tipo de cosas

Por otra parte, niños y niñas tienden a dar continuidad a las acciones, costumbres y prácticas de sus referentes cercanos (jóvenes o adultos dependiendo con los sujetos que establezca relaciones) generando muchas veces que ellos evadan la responsabilidad frente a las prácticas de riesgo que llevan a cabo. Al ver que sus modelos a seguir no padecen ninguna retaliación frente a comportamientos que para ellos desde lo moral no son buenos, niños y niñas los llevan a cabo pensando que no genera consecuencias.

En ese sentido, niños y niñas construyen una subjetividad enmarcada en la no existencia de límites para la acción y que cualquiera que lleven a cabo pueden desarrollarla sin inconvenientes, pero, cuando se presenta una situación que afecte de manera directa su subjetividad, las reacciones son impredecibles:

Nñ: pues a veces, porque me da como envidia, que alguien me gane en algunas cosas, que alguien sea mejor que yo en algunas cosas...

I: y ahí ¿cuál es el riesgo?

Nñ: ehhh, que de pronto, de pronto... una seria suicidarme, otra seria que yo mate a la otra persona.

En este orden de ideas, aparece de los procesos de interacción entre pares, tensiones constantes, que pueden configurarse como prácticas de riesgo. La competencia por destacarse entre las y los demás hace que niños y niñas jueguen por senderos de intolerancia a la frustración y a reconocer los 
logros de sus pares y eso se asocia a los niveles de exigencia que los diferentes actores y el contexto ejercen sobre ellos, haciendo que la tensión entre las infancias sea permanente.

\section{Las prácticas de riesgo como interrogante del orden institucional.}

Por ultimo en éste ítem los resultados se desarrollan a la luz de 4 subcategorías: La infancia en tensión con la lógica institucional, La infancia invierte las relaciones de poder, Descentramiento del adulto para darle lugar al niño y El riesgo como dispositivo que favorece la autonomía de la infancia, a través de ellas se asume el riesgo como un interrogante del orden institucional.

\section{La infancia en tensión con la lógica institucional.}

Dadas las posibilidades que el riesgo ofrece respecto a la alteración de lo instituido en un contexto, para el caso de los niños y niñas usualmente emerge de sí mismos un proceso de contención de eso que se desea, hay una prueba permanente de represión hacia su subjetividad de tal manera que ello garantice distancia frente a las prácticas riesgosas.

Respecto a lo anterior, los procesos reflexivos son orgánicos y dan lugar a la contención de la acción, destacando como ingrediente principal el temor al castigo, ello no quiere decir que se inhiban puntos de quiebre, donde las infancias eventualmente en medio de la tensión obran con decisión y la exploración irrumpe y da lugar a la configuración del riesgo.

I: ¿Porque creen que hacer copia es un riesgo?

Nñ: Porque si tú haces copia nunca vas a aprender y la profesora te puede regañar y es un riesgo a perder un examen (...) y a que tus papás te regañen.

I: ¿Lo has hecho?

Nñ: No, nunca... por miedo a que me pillen y a que me regañen.

Aparecen los adultos (padres y madres de familia y docentes) reconociendo el desborde del rol protector que limita las posibilidades de exploración, agencia y en general de constitución subjetiva en los niños y niñas, se hace evidente el dilema que se liga ante las figuras de cuidadores versus el rol de facilitadores y promotores del desarrollo, en tanto las relaciones de afecto justifican sus conductas de vigilancia y dominio.

De lo anterior deriva un adulto que subestima continuamente la capacidad crítica y de agencia de los niños y niñas frente al riesgo, bien porque se asume a la infancia como una categoría social 
cargada de ingenuidad, desconocimiento e impulsividad o por el contrario como las y los seres sin la capacidad de premeditar y hacer.

I: ¿Te has sentido alguna vez en situación de riesgo?

Nñ: Nunca, porque siempre mis papás me protegen.

Mamá 3: (...) los niños ahorita están acostumbrados a que uno como papá le diga: <<Oiga no se bote allá porque eso es malo $>>\ldots$ digamos que uno les está quitando la capacidad de pensar... <<Oiga, ¿esto es bueno para mí o esto es malo?>>, entonces digamos que uno por sobreprotegerlos a veces comete ese error y es un problema más porque uno no les está enseñando a que ellos decidan.

Por su parte las tensiones entre las infancias modernas y las posmodernas ha implicado constantes discusiones respecto al beneficio o no en el uso de las Tic's y su relación constante con el riesgo, en este sentido las y los adultos suscriben el temor y la incertidumbre a lo que la cultura audiovisual y tecnológica ha traído para los niños y niñas contemporáneos y por ende se justifican las restricciones o limites en su uso.

A pesar de ello la tecnología es reconocida como un factor de desarrollo, inherente a los procesos evolutivos del sistema y en consecuencia inevitable en las lógicas de niños y niñas, quienes a su vez reproducen la postura del pensamiento adulto y por ende reiteran los discursos en los que se debe limitar el uso y mantener una conducta preventiva, fundamentalmente cuando de redes sociales se trata.

Papá: (...), ahoritica pegado a la tecnología vienen muchas más porquerías, muchas más cosas que uno se queda pensando, ¡pero!, es algo como... iparadójico!... y es que ellos son más vivos, más despiertos, más inteligentes (...)

El riesgo es configurado desde las nuevas comprensiones del concepto de comunidad, la comunidad como ausente en las sociedades posmodernas e invisible en el rol protector de niños y niñas, quienes por su parte deben anticiparse, privarse de su instinto a confiar y reconfigurar el sentido de las relaciones sociales contemporáneas, en esta medida la ruptura del tejido social, coloca nuevos escenarios donde el riesgo tiene lugar para las infancias y en donde deben enfrentar la incertidumbre y por ende conducir sus prácticas. 
Mamá 3: (...) por ejemplo acá en Bogotá todo el mundo es así... que nadie me toque, que nadie... porque me van robar, me van a hacer... mientras que por ejemplo yo soy de un pueblo si?, entonces allá por ejemplo donde yo me crie, jum!, (...) yo por ejemplo callejeaba mucho y me la pasaba jugando con amigos y en la calle y hasta las 10 de la noche y juegue y haga y todo (... ) entonces es muy diferente la crianza mientras que acá por ejemplo para mi es difícil entender... por ejemplo cuando sumercé dice que no conoce a sus vecinos, que uno no sabe quién está al lado, que uno tiene que estar pendiente que le van a robar a sus hijos (...)

Desde la escuela aparece un escenario explícito de tensión ante las prácticas que se conciben como riesgosas durante la infancia, al concebirse como un ente previsivo y de control, existe de su parte una acción sucesiva frente a la infinitud del riesgo y por ende una preocupación permanente por dar trámite a todo factor, situación o conducta que lo genere, de este modo los procesos de gestión del riesgo, de manera imprevista, imponen y moldean de alguna forma la construcción subjetiva de niños y niñas limitando su espontaneidad ante la exploración, el juego y el trato con el otro.

La condición normativa, protocolaria y conservadora, imprime límites constantes en las dinámicas infantiles y en este sentido, dirige las formas de vivir en la escuela y da por hecho que el riesgo está implícito en la transgresión de la norma.

Nñ: (...) Nos gusta la zona verde porque, pues, porque a veces nosotros nos metemos allá, jugamos y nos regañan...

I: ¿Y los regañan?

Nñ: Sí, porque no es una cancha es una zona y pues por lo que dicen las hermanitas, es una zona restringida"

\section{La infancia invierte las relaciones de poder.}

A través de las prácticas riesgosas la infancia logra subvertir las relaciones de poder respecto a los adultos cuando se entran en escenarios donde el desafío es trazado por las y los niños, en esta lógica las tensiones se hacen evidentes en tanto son ellos quienes asumen el control y las posibilidades de logro, la practica riesgosa aquí no es oculta y se reta al adulto quien posee menos conocimientos, capacidades y habilidades. 
Mamá 1: (...) ese día me dijo mi hijo: <<No mami, yo monto solo $>>$ y yo: $<<$ No hijo, usted no puede montar solo >>, ese caballo era de los grandotes y yo: $<<$ ¡no, no, no! >>, $<<$ Entonces móntese usted primero a ver qué va a hacer >> así me desafió, y yo: <<Venga y me monto $>>$, oiga y me he caído de ese caballo, ¡Me caí!, (...) y mi hijo se orinó de la risa de verme que me caí, le dije: <<¿Hijo usted se está burlando de su mamá?>> y dijo: <<Ay pero que usted siempre dice que puede y no puede〉>, oiga y se montó ese niño en el caballo y chum chum chum ru chum (...)

El riesgo juega un papel importante ante los deseos e intenciones de la infancia de alterar el orden institucional, de perturbar el mundo adulto, la travesura como practica riesgosa en este ámbito se asume con pleno conocimiento y su ocasión no es exclusiva del juego o la diversión, hay un interés explicito por hacer del riesgo un mecanismo de transfiguración de las relaciones y el entorno, se actúa aun midiendo los efectos posibles.

Mamá 2: yo estudié con monjas, (...) y yo me ofrecía a arreglar el salón, pero es que había una monjita que me la tenía montada, eso lo pellizcaba a uno, le daba con la regla así... a mi cada rato en la tapia del colegio me ponían así, que me viera todo el mundo y yo en medio de la clase y eso era semanalmente... y yo era tremenda. Y yo cogía a barrer el salón, el segundo piso me gustaba... yo sabía a qué horas pasaba la monjita peleando y llegaba y amontonaba toda la basura y cuando ella paraba en ese sitio siempre, yo llegaba y escondía la basura y salía corriendo (...)

\section{Descentramiento del adulto para darle lugar al niño.}

En consonancia con el análisis anterior aparece un elemento de tensión a lo instituido en la lógica adulta, razón por la cual su descentramiento da lugar y permite la producción del riesgo en la infancia, es decir, las prácticas de riesgo en niños y niñas en ocasiones desinstala del mundo adulto la conducta habitual de previsión, dominio y control, permite ser a la infancia, ponerse a prueba, medirse, explorar.

Mamá 1: después de lo que me pasó con él yo empecé a soltarlo... $<<$ Mami es que yo sé nadar >>, yo le dije: <<Es que tú no sabes nadar >>, << que sí, que sí sé nadar $>>$ y yo: $<<$ Ah bueno, vaya tírese a la piscina a ver qué le pasa, que usted no sabe nadar $>>\ldots$ oiga y se tiró ... iy se tiró!... cuando él empezó, (sonidos de ahogo)... ¿entonces que hice yo?, le pasé un palito, que él agarrara el palo (...) 


\section{El riesgo como dispositivo que favorece la autonomía de la infancia.}

Cuando la infancia se despliega las prácticas de riesgo constituyen notablemente un proceso que reivindica su condición subjetiva, favoreciendo su autonomía y sus posibilidades de ser y estar en el mundo, se denota una homologación del riesgo con la condición innata de ser niño o niña, en esta medida un despliegue pleno de la infancia implica la ausencia de la mirada adulta, tomar distancia de su mundo y garantizar una experiencia bajo sus propias condiciones y significados.

De lo anterior deriva el interés de los y niñas por emprender aquellas prácticas en las que la imitación provoca una circunstancia riesgosa, la emulación del mundo adulto constituye un ingrediente y una provocación para la búsqueda del riesgo, aun cuando esto insiste en disponer un ambiente que le permita independencia.

Mamá 1: ...pues mi papá es militar o fue militar y yo veía que los militares se lanzaban del avión como los paracaidistas y yo decía, "ay tan bonito eso, tan chévere eso..." y un día con unos amigos nos fuimos, eso fue acá en Bogotá en la artillería... a jugar y resultamos subiéndonos en unos palos diciendo que ese era el avión, nosotros disque encaramados por allá y uno de ellos se resbaló y yo no alcancé a agarrarme y me caí y me partí un brazo... y pa' que me sacaran de allá porque yo estaba a escondidas (...)

Por ultimo para los niños y niñas el riesgo como mecanismo favorecedor de la autonomía se refleja en los imaginarios en los que la infancia presume control permanente frente a ciertos factores de riesgo, los campos inexplorados o desconocidos no constituyen para ellos y ellas un elemento que promueva el riesgo, por el contrario, se confía en la capacidad de autorregulación y de condicionamiento de lo que expone el entorno.

Nñ: (...) entonces el niño no escogió ninguna de esas y cogió el carro y se mató, o sea descansa en paz, pero yo nunca lo voy hacer en la vida, eso ah, ah, no. Les digo esto que si un niño va a hacer eso mejor dígale a la policía y listo ya no se complica la vida.

Atado a la premisa de sus posibilidades de autocontrol permanente, las infancias demuestran su capacidad reflexiva y de decisión, reconocen su oportunidad para poner en juego la razón y así autodeterminarse. 


\section{I: Para ti ¿qué es el riesgo? (...)}

Nñ: ehhh, para mí, es un peligro, porque... pues... el riesgo no... digamos, o sea... tú decides si lo haces o no, porque todos tenemos decisiones, sabes que está bien y que está mal. El riesgo, digamos si tú sabes que... que hay un parlante y si tú lo tocas, te vas a electrocutar, y tú sabes que eso está... es peligroso, eso es un riesgo... tú tienes que alejarte de ese lugar (...).

\section{Discusión}

\section{Las prácticas de riesgo en la construcción de subjetividad política en niños y niñas del ámbito escolar.}

En atención a los planteamientos expuestos desde la línea teórica y en relación con los hallazgos desarrollados anteriormente, se entiende cómo la subjetividad política de niños y niñas escolarizados logra configuración a través de las comprensiones y acciones que tejen alrededor de las prácticas de riesgo, en este sentido se reconoce que como muchos fenómenos, situaciones, elementos, factores, dinámicas, el riesgo atraviesa e incide en la construcción subjetiva de la infancia, dado el carácter reflexivo y de agencia que éste implica.

Entendiendo que la subjetividad en niños y niñas implica un despliegue de autonomía, interrogación, creación, participación, valoración, decisión, entre otros, se reconoce cómo alrededor del riesgo todos estos elementos tienen la posibilidad de ser, la posibilidad de constituirse desde el momento en que la infancia genera significados, le da su propio sentido y reconoce la causa y la forma en que las prácticas de riesgo tienen lugar. El riesgo como cualquier otra experiencia en el mundo infantil garantiza la oportunidad de interactuar con el otro, de situarse en un contexto y movilizarse de acuerdo al sentido que se le da, de apropiarse de sus dispositivos y en general de transformar la realidad conforme a sus intenciones y deseos.

(...) entidad cambiante que siempre está en proceso de constituirse, que se transforma en función de las experiencias que cada niño y niña mantiene con otras personas y con sus propias experiencias de conocer y de ser (experiencia de sí), que se aprende e interpreta intersubjetivamente, mediante interacciones sociales con otros sujetos y contextos culturales. La subjetividad infantil, vista como un modo en que el niño y la niña hacen en el mundo, hacen con el mundo y se configuran en el mundo, es un modo de hacer con lo real, con la propia experiencia, en la cual se reconoce el devenir de la subjetividad infantil. (Espinosa, 2013, p. 22) 
En tanto las prácticas de riesgo permean la constitución subjetiva de las y los niños, es propio situar elementos específicos que dan lugar a esta afirmación, para ello se destaca la comprensión y el sentido que las infancias definen alrededor del riesgo, las condiciones del contexto que trazan posibilidades para que prácticas de este orden puedan emerger en el niño y niña escolar y por último la interrogación de la dimensión institucional no solo vista desde la práctica de riesgo en si misma sino como un elemento contingente de la experiencia subjetiva de las infancias.

Es así como los resultados del estudio revelan el significado que la infancia atribuye al riesgo, asociándolo de manera explícita y directa a toda condición de peligro, de amenaza, se impone un carácter nocivo que atenta con el bienestar individual y colectivo, el riesgo siempre impondrá su condición de daño que genera desequilibrio respecto a una instancia futura. De allí se entiende la construcción social que se teje alrededor del riesgo, en tanto el adulto (principalmente cuidadores y padres y madres de familia) en el proceso intersubjetivo transfiere ciertas nociones y es en el discurso en donde la infancia las reproduce.

El aliento social a adoptar riesgos reduce las seguridades que antes estaban en las familias y deja las consecuencias a una evolución no controlable centralmente. Los riesgos se transfieren entre los sistemas funcionales, y que las cosas salgan bien depende ahora de que los sistemas Funcionales puedan soportar con sus propios medios los riesgos de los otros sistemas. Es por ello que el futuro aparece como un desafío posiblemente ya incontrolable. (Luhman, 1992, p. 153)

De manera particular la infancia a través de la narración de experiencias, ubica al riesgo en un escenario de temporalidad donde el efecto de una práctica de este orden se hace evidente en el futuro, pero deviene de una expresión de desavenencia respecto a un pasado que incomoda, un pasado que quiere ser fracturado y de allí que se asuma el riesgo como una forma de lanzarse hacia la búsqueda de alternativas, los niños y niñas posmodernos interpretan del consumo de sustancias psicoactivas, de la conducta suicida, del pandillismo, de las relaciones sexuales a temprana edad y sin protección, una forma de reorientar sus condiciones de vida, de reconfigurar los sentidos que tienen de ella, respecto a ello Giddens (2007) es explícito en afirmar "La idea de riesgo supone una sociedad que trata activamente de romper con su pasado, la característica fundamental, en efecto, de la civilización industrial moderna.”(p. 13) 
Es así como la capacidad reflexiva que recae en el sujeto, sigue concibiéndose como un elemento inherente a su condición humana y aun cuando el riesgo guarda relación con lo desconocido, lo imprevisto, lo incontrolable, los niños y niñas reconocen su oportunidad para premeditar y contemplar cálculos ante situaciones revestidas de riesgo, reconociéndose a partir de allí la emergencia de lo subjetivo, solo es a través del elemento subjetivo que la práctica riesgosa cobra vida y esta a su vez en un ejercicio reciproco alimenta las posibilidades del niño y la niña de ser, de dirigirse, de decidirse.

(...) se viene considerando como una decisión que tal como se puede prever, se lamentara más tarde en el caso de que ocurra un desafío que se esperaba evitar. El cálculo de riesgos se trata de un cálculo temporal. En relación con un futuro incierto, debiera encontrarse un fundamento seguro para las decisiones. El desafío puede ser evitado. Sin embargo, pueden aceptarse acciones riesgosas, que por lo tanto impliquen un desafío, siempre y cuando este se justifique de acuerdo a su magnitud y probabilidad de ocurrencia. (Luhman, 1992, p. 150)

Alrededor del contexto se reconocieron las disposiciones que éste genera para que un hecho riesgoso tome lugar en la experiencia de niños y niñas, en tanto su estructura y dinámicas contienen todo aquello para que la infancia en su "condición de vulnerabilidad innata" permanezca expuesto, son los adultos quienes fundamentalmente identifican cómo desde la sociedad posmoderna aparecen factores que hacen acuciante la practicas de riesgo infantiles, en este sentido la tecnología, la cultura audiovisual, el consumismo, los medios de comunicación, la nuevas dinámicas en la familia y lo comunitario como ausente, disponen nuevas relaciones y comprensiones del peligro. De allí las y los niños reconocen el uso de las TIC'S y la fractura de los lazos comunicativos en la familia como el principal componente para el riesgo, lo que para Luhman (1992) significa el aumento en los niveles de complejización de la sociedad, cuestión incesante que traerá implicaciones frente al dominio o no del riesgo social.

En este sentido no se desliga el riesgo manufacturado ${ }^{5}$ de la capacidad de agencia en las y los niños y su relación con lo propio del entorno, por su parte, la institucionalidad reconoce la disposición del sistema para crear o no condiciones y las y los niños su posibilidad para constituir la amenaza desde allí, para saber cómo moverse y tomar o no partido ante la circunstancia, respecto a ello Luhmann (1992) indica:

\footnotetext{
${ }^{5}$ De acuerdo a las reflexiones de Anthony Giddens (2007), constituye toda práctica premeditada y ejecutada por la o el sujeto, que no es ocasionada ni de manera espontánea, ni por causa exclusiva de la naturaleza o el entorno.
} 
(...) la sociedad conoce la forma de contextualizar el comportamiento ante el riesgo. El sistema funciona cuando la comunicación distingue los distintos códigos y los sistemas funcionales individuales. Se corren los menos riesgos posibles tratando de aprovechar las oportunidades y mientras no suceda así, se decide esperar una posición adecuada. (p. 152)

De lo anterior se destaca el carácter tensionante que subyace de los mundos simbólicos de niños y adultos, su distancia permanente se identifica aquí como elemento propio del escenario donde tiene lugar la realidad de la infancia y que continuamente dispondrán puntos de fuga representados en las prácticas de riesgo, esto mismo constituye la oportunidad de ser para una subjetividad que toma fuerza y se reivindica cotidianamente.

P. A: Sin embargo, hoy todo lo que está prohibido.

F.D.: ¡No, no está prohibido! (...). No está prohibido, ya sea en una guardería, donde hay cincuenta niños y donde los más cachondos se reúnen en una esquina y todos cuentan sus historias. Pero no sabemos nada, porque los niños se resisten a los adultos. (Doltó, 2010, s.p)

La subjetividad política en este caso representada en la práctica de riesgo infantil, constituye un elemento incidente para la interrogación del orden institucional, es desde la incertidumbre que se altera lo instituido, es desde lo imprevisible que el sistema pierde equilibrio al no hallar las herramientas para mantener el control y desde aquí la trasgresión a lo normativo y moral es el mejor apellido que se le asigna a la práctica de riesgo de sus niños y niñas, en este sentido Bustelo (2005) destaca las tensiones generadas con las lógicas de la institucionalidad ante aquello que no es "normal" ante aquello que no es permitido.

La normatividad hace alusión a un "deber ser" cuyo "deber" se impone como práctica discursiva de poder. En el caso de la infancia y la adolescencia es un "deber" despótico al que todo "se debe". Es un deber, sin apelativos, a los adultos. La imparcialidad a su vez se refiere a su supuesto carácter "objetivo": coincidencia "pura" y plena con una "realidad" ante la cual sólo cabe someterse. (Bustelo, 2005, p.257)

De esta manera desde la postura institucional, el juego y la exploración tienen un carácter de riesgo implícito a través del cual niñas y niños inhiben su capacidad para razonar, se convierten en seres exclusivamente instintivos que de manera inconsciente rompen con las reglas, de manera contraria las infancias reconocen las posibilidades de decisión que siempre hay frente a un marco normativo, destacan sus posibilidades ante la reflexión, sólo que en sus intereses prima jugar con el 
riesgo. Al respecto Giddens (2007) rescata el carácter sensible y placentero que trae consigo el riesgo y el cual permite fracturar lo tradicional, lo que "debe ser".

La aceptación del riesgo, con todo, es también condición de excitación y aventura, pensemos en el placer que mucha gente extrae de los riesgos del juego, de conducir deprisa, de los devaneos sexuales o de las piruetas de una montaña rusa en un parque de atracciones (...) El riesgo es la dinámica movilizadora de una sociedad volcada en el cambio que quiere determinar su propio futuro en lugar de dejarlo a la religión, la tradición o los caprichos de la naturaleza. (Giddens, 2007, p. 13)

Con lo anterior se entiende que la subjetividad en la infancia se configura a través de diversas formas y el riesgo es tan sólo una de ellas, pero a partir de la cual se garantiza la activación de sus propios lenguajes, visiones, significados, deseos, intenciones y capacidades, y donde la institucionalidad es vista desde su influencia, desde los dispositivos que provee, pero también desde el desequilibrio al que está expuesta continuamente cuando el niño y la niña irrumpen, instituyendo sus sentidos, sus mundos simbólicos y la posibilidad de contenerlos o de ponerse en dialogo son sólo algunas alternativas.

No decimos que "las instituciones no existen", que "la familia, la escuela, la universidad no sirven para nada", "ya no se educa", "la escuela dejó de ser necesaria"..., no. Lo que señalamos es que en tanto instituciones de la modernidad, ellas no son lo que eran (...) se trata entonces de crear nuevas escenas de experiencia, de aprendizaje, de relación social con los niños (...) Los niños de hoy son lo que son y con ellos tenemos que vérnoslas. ¿Cómo nos relacionamos, en tanto adultos, con esos modos que tienen de habitar el mundo? ¿Somos capaces de leer en los desacoples entre consignas institucionales y respuestas subjetivas algo más que una categoría patológica? (Lajarraga, 2012. p. 321)

\section{A modo de conclusión.}

Partiendo de los antecedentes del estudio, se reconoce en primer lugar que desde la investigación cualitativa hay una oportunidad para abordar la temática del riesgo desde la categoría conceptual propuesta, es decir, se invita a que el abordaje temático se amplié a la noción de prácticas de riesgo y con ello que los factores externos y el desconocimiento del sujeto no sean las únicas variables que se contemplen en este tipo de estudios, por su parte que la intencionalidad y toda la carga subjetiva de los sujetos sea contemplada. 
Respecto a los hallazgos de la investigación, las prácticas de riesgo en niños y niñas se constituyen en una expresión de las formas en que configuran su subjetividad política, se reconocen como un medio en el que demuestran al sistema sus formas de ser y estar en el mundo y de allí que devengan diversas tensiones con el orden institucional, con el mundo simbólico de los adultos.

No obstante, se hace evidente que el riesgo para las infancias se configura en medio de quiebres, a través de los cuales instituyen sus comprensiones, sentidos y en general sus formas de ver y querer hacer en el mundo, pero que de manera cotidiana mantienen una relación de control o dominación por la institucionalidad, por los marcos normativos y morales (la religión elemento principal) de los cuales también tienden a reproducirse ciertos discursos y a configurarse conductas que cumplan con las expectativas del adulto.

De lo anterior, el juego y la exploración para las y los adultos constituyen en gran medida un factor incidente para las prácticas de riesgo en la infancia, atribuyéndoles un carácter negativo dados los niveles de exposición que generan, sumado a ello en un contexto en el que la sociedad posmoderna se asume como vulnerable ante los usos y amenazas de las tecnologías de la información y comunicación.

En este sentido son los adultos quienes colocan en gran parte la responsabilidad al entorno de las prácticas de riesgo que configuran sus niños y niñas, aun cuando no desconocen sus habilidades, conocimientos, intenciones y su capacidad de agencia, no se reconocen estos últimos como elementos constitutivos, por el contrario, son los niños y niñas quienes destacan sus posibilidades de reflexionar y decidir ante el riesgo, incluso sobredimensionan sus niveles de confianza respecto al autocontrol y dominación de los factores de riesgo. 


\section{Referencias}

Acevedo, A., Vargas, F., (2000) Sociología del riesgo, En Estudios sobre las culturas contemporáneas vol VI, No 11 Universidad de Colima México. Recuperado de https://mail.google.com/mail/ca/u/0/?shva=1\#search/julianas $1210 \% 40$ gmail.com/158d0fbeef0a9c $\underline{\text { fc?projector }=1}$

Beck, U., (1998). La sociedad del riesgo, hacia una nueva modernidad. Recuperado de http://davidhuerta.typepad.com/files/beck-ulrich-la-sociedad-del-riesgo-hacia-una-nueva$\underline{\text { modernidad.pdf }}$

Bustelo, E.S., (2005) Infancia en indefensión. En Salud colectiva vol.1, No 3, Universidad Nacional de Lanús, Buenos Aíres, Argentina Recuperado de http://www.scielo.org.ar/scielo.php?pid=S1851-82652005000300002\&script=sci_abstract

Bustelo, E.S., (2007) El recreo de la infancia argumentos para otro comienzo. Buenos Aires, Argentina: Siglo XXI editores Argentina.

Corea, C. Lewkowicz, I. (1999). ¿Se acabó la infancia? ensayo sobre la destitución de la niñez. Recuperado de https://es.scribd.com/doc/212477684/COREA-LEWKOWICZ-Se-acabo-lainfancia-pdf

Dolto. F., (2010). Entrevista a Françoise Doltó. Recuperado de: http://es.paperblog.com/entrevistaa-francoise-dolto-200950/

Espinosa, A.M., (2013) Configuración de la subjetividad en la primera infancia en un momento posmoderno. Recuperado de https://dialnet.unirioja.es/descarga/articulo/4814912.pdf

Giddens. A. (2007). Un mundo desbocado, los efectos de la globalización en nuestras vidas. Recuperado de 
http://eva.universidad.edu.uy/pluginfile.php/506145/mod_resource/content/1/Giddens,\%20Antho ny\%20-\%20Un\%20mundo\%20desbocado.pdf

Heidegger, M. (1926) Ser y tiempo, recuperado de

http://www.afoiceeomartelo.com.br/posfsa/Autores/Heidegger,\%20Martin/Heidegger\%20\%20Ser\%20y\%20tiempo.pdf

Hernández, R., Fernández, C y Baptista M. (2010). Recolección de datos cuantitativos. En: Metodología de la investigación, 5a. Edición. Recuperado de http://es.slideshare.net/cenzontle/8$\underline{\text { recoleccin-de-datos-cuantitativos }}$

Lajarraga, H. (2012). La subjetividad del niño en la posmodernidad. Recuperado de: http://www.scielo.org.ar/pdf/aap/v110n4/v110n4a08.pdf

Luhmann, Niklas., (1992). Sociología del riesgo. Recuperado de https://analisisinstitucionaluba.files.wordpress.com/2013/08/sociologia-del-riesgo-niklasluhmann.pdf

Mancini. F., (s.f.). Riesgos sociales en sociedades complejas. Una mirada desde la sociología contemporánea. Recuperado de: http://actacientifica.servicioit.cl/biblioteca/gt/GT31/GT31_ManciniF.pdf

Martínez, J.E., (2010). ¿Qué hay más allá de la juventud? Una lectura desde la política de los acontecimientos. En Tabula rasa, revista de humanidades No 14. Recuperado de: http://www.redalyc.org/articulo.oa?id=39622094018

Obregon, B.I., (s.f). Conductas de riesgo convencionales. Centro de información y educación para la prevención de abuso de drogas. Recuperado de https://mail.google.com/mail/ca/u/0/?shva=1\#search/julianas1210\%40gmail.com/158d0fbeef0a9c fc?projector $=1$

Palladino, E., (2009) Otros aportes al psicoanálisis. En Palladino. Infancia sociedad y educación. Desarrollo de la subjetividad. (pp. 129 - 151). Buenos Aíres, Argentina. Editorial Espacio. 